\title{
28 Research Square \\ Unexpected DMD Gene Mutations Detected by CMA and CNV-seq in amniotic Fluid and Aborted Fetus Samples
}

\author{
Qiuhua Wu \\ Northwest Women's and Children's Hospital \\ Lihui Yang \\ Northwest Women's and Children's Hospital \\ Qiujie Jin \\ Northwest Women's and Children's Hospital \\ Rui Wang \\ Northwest Women's and Children's Hospital \\ Wen Zhai \\ Northwest Women's and Children's Hospital \\ Yating Wang \\ Northwest Women's and Children's Hospital \\ Fengrui Shi \\ Northwest Women's and Children's Hospital \\ Wenjing Cheng \\ Northwest Women's and Children's Hospital \\ Bo Cai \\ Northwest Women's and Children's Hospital \\ Rong Qiang \\ Northwest Women's and Children's Hospital \\ Chao Lou ( $\square$ loucha0811@126.com ) \\ Northwest Women's and Children's Hospital
}

\section{Research Article}

Keywords: Duchenne muscular dystrophy (DMD), Becker muscular dystrophy (BMD), hereditary diseases, Dystrophin gene

Posted Date: April 5th, 2021

DOl: https://doi.org/10.21203/rs.3.rs-376139/v1

License: @ (i) This work is licensed under a Creative Commons Attribution 4.0 International License. Read Full License 


\section{Abstract}

Background: Duchenne muscular dystrophy (DMD) and Becker muscular dystrophy (BMD) are common X chromosome-linked recessive hereditary diseases. The mechanism is that the exon mutations of anti-myatrophy protein gene (Dystrophin gene) and lead to muscle dysfunction. Prenatal diagnosis can prevent the birth of children with defects and have good clinical significance.

Methods: CMA and CNV-seq were used to detect the amniotic fluid after amniocentesis,. CNV-seq was used to detect spontaneous abortion tissue. The DMD gene mutations were found in 6 amniotic fluid samples and one spontaneous abortion sample. DMD gene mutations were confirmed by MLPA and new DMD mutations were found.

Results: CMA found DMD mutations :1.Xp21.1, 75.5kb del (E52-53); 2.Xp21.2, 334.92kb dup (E61-79); 3.Xp21.2, 292.25kb dup (E58-74); 4.Xp21.1, 374.20 kb dup (E45-51). CNV-seq found DMD mutations: 5.X p21.2, E64-79 dup; 6.X p21.1, E1-7dup; 7.Xp21.1, E 44-52 del.

Conclusions: 4 fetuses harboring DMD gene mutations were found by CMA, 2 fetuses and 1 induced abortion carrying DMD gene mutations was detected by CNV-seq. CMA/CNV-seq jointed with MLPA test can provide more comprehensive evidence for prenatal diagnosis.

\section{Introduction}

Dystrophin gene(DMD gene) is located in chromosome Xp21.1, mutations in this gene can cause DMD or BMD [1]. Most of the patients were male, DMD incidence among live-born boys is nearly $1 / 3500$, the symptom of walking disability may emerge at $3 \sim 5$ years old, getting worse and worse step by step when he grow up until losing ability to walk, died at about 30 years old because of heart and lung failure [2]. BMD incidence among live-born boys is about 1/20000, clinical manifestations are milder than DMD, generally have late onset age and longer life cycles. One of DMD/BMD problems is that patients with no family history can not usually be found before birth, but after the new technologies such as genome-wide high resolution microarray analysis (CMA), single nucleotide polymorphism (SNP)and high-throughput next generation sequencing technologies (CNV-seq) are widely used in prenatal diagnosis [3-5], more and more minor structural abnormalities such as chromosome microdeletions and microduplications have been detected. There may even be some unexpected findings that do not totally match the patient's clinical indications,such as DMD/BMD. We found seven DMD gene mutations cases by CMA and CNV-seq accidentally, and then used MLPA (Multiplex ligation-dependent probe amplification) to confirm the mutations and found new mutations( Fig.1,Fig2).. The mutations may lead to fetal DMD or mild BMD after mutations analysis.

\section{Materials And Methods}

\section{Samples}

Patients with abnormal serological Down screening, B ultrasound abnormality or high NIPT(Non-invasive Prenatal Testing) risk came to our department for invasive prenatal diagnosis. The spontaneous abortion sample was send from the Department of Gynaecology and Obstetrics, Northwest Women's and Children's Hospital, Xi'an, China.( Tab.1). All methods of prenatal diagnosis were introduced to patients, consents were signed by patients, and the tests were selected by patients voluntarily.

\section{aCGH test}

Getting $10 \mathrm{ml}$ amniotic fluid by amniocentesis, cells in amniotic fluid were collected by centrifugation and divided into two $1.5 \mathrm{ml}$ EP tubes, one tube was used for experiments, the other was stored at $-20^{\circ} \mathrm{C}$. Using PureGene tissue extraction kit (Qiagen) to extract genomic DNA. Marking, purifying, hybridizing, washing and scanning the DNA according to Agilent $8 \times 60 \mathrm{~K}$ chip detection process. Uploading the scanning data to Cytogenomics software (Agilent Technologies) and analyzing the scanning data preliminarily. At the same time, the scanning data was converted into .zip file and uploaded to Genoglyphix (Perkin Elmer), using public and laboratory databases such as DGVIDECIPHER ISCA $O$ OMIM $\square$ ClinVarIPubMed to analyze pathogenicity of CNVs fragment $\geq 100 \mathrm{~kb}$. The CNVs were classified into three categories according to the 2015 ACMG guidelines :(1) Pathogenic CNVs; (2) Variant Unknown Significance (VUS) CNVs; (3) Benign CNVs.

\section{CNV-seq}


Getting amniotic fluid was described as in CMA test. The extraction of gnomic DNA from amniotic fluid and skin of aborted fetus was taken by DNeasy Tissue Kit (69506) (Qiagen)[6]. Using Chromosome CNV Detection Kit KR0040 (Berry Genomics Corporation, Beijing, China) to detect CNV-seq. The procedure was performed as described before [7]: Nearly $50 \mathrm{ng}$ DNA was hydrolyzed by restriction enzymes to obtain DNA fragments at an average size of $200 \mathrm{bp}$ and established DNA libraries by small DNA fragments end filling, adapter ligation, and PCR amplification. To determine all sequences on the NextSeq 500 high-throughput sequencing platform (Illumina USA). Compared the sequences with h19 Human Genome Database by parallel alignment software and analyzed pathogenicity of CNVs fragment $\geq 100 \mathrm{~kb}$ as described in CMA test.

\section{MLPA test}

DMD Gene Detection Kit was SALSA MLPA kit DMD P034/P035( MRC company, Holland) $\$ ABI3500DX Genetic Analyzer(AB Applied Biosystems) was used for capillary electrophoresis, and Coffalyser NET software was used for data analysis.

\section{Discussion}

Mutations in DMD genes can lead to muscular dystrophy (DMD or BMD). If the deletion or duplication mutations in DMD gene destroys the reading frame and result in the anti-myatrophin protein content less than $3 \%$ or can't produce myoatrophin, patients show DMD. If deletion or duplication mutations keep the reading frame intact or less destoryed, it leads to the anti-myojiatrophy protein keeping part of the function, patients show BMD. But there are also a few patients who DMD gene deletion or duplication did not alter the reading frame, it still show DMD. [8]

The main DMD gene mutation type of is partial deletion or repetition of 79 gene exons, nearly account for $60 \%$ $70 \%$ of all mutation types. The rest are point mutations, minor insertion or deletion mutations|. Despite many studies on gene therapy in DMD, such as exon hopping, readout of nonsense stop codon or injection of vectors with full DMD gene, gene therapy still faces great challenges and dilemmas[9]. There is still no effective treatment for DMD/BMD patients until now [10,11], early diagnosis and early treatment can prolong the survival age and improve the quality of life of DMD patients, but can not be cured. DMD patients with no family history of hereditary diseases can not usually be found before birth [12-16]. A majority of DMD patients develop clinical symptoms around age 3. But the results of serum creatine kinase level, neuroelectrical trophysiological examination and DMD gene detection were clearly diagnosed until 5 years old, so genetic counseling and screening for DMD genes prior to or in early pregnancy are particularly important, prenatal diagnosis is an important approach to prevent the birth of the patient with a family history of DMD/BMD or with no history.

High-resolution genomic CMA and high-throughput next generation sequencing CNV were used in prenatal diagnosis not only detect chromosomal microdeletion and microduplication syndrome, but also helped to detect single gene disease caused by gene deletion or duplication, can improve the diagnosis rate of disease. In this study, the pregnancy of all male fetuses were terminated. Two female fetuses were born: Case6 is normal; but Case 3 showed upward bent legs and heavy hair, WES did not find problems. One female fetus (Case 5) was aborted.,( data of 7 patients showed in Tab 1).We compared the DMD gene mutations between fetus and mother, found some mutations inherited from mother(Fig 1) and some didn't(Fig 2), it also reveals the importance of prenatal diagnosis because the mother is carrier or healthy woman, and with no family history of DMD. So it is beneficial to the correct evaluation of fetal prognosis in prenatal clinical consultation, and provide a more comprehensive advice to decide if the pregnancy should continue or be terminated to prevent the birth of children with defects.

Table 1

Clinical and experimental data of the 7 analyzed patients 


\begin{tabular}{|c|c|c|c|c|c|c|c|c|}
\hline Case & Weeks & Gender & Medical history & Sample & Results & MLPA & Inheritance & $\begin{array}{l}\text { Follow- } \\
\text { up }\end{array}$ \\
\hline \multirow[t]{2}{*}{1} & $24+1$ & male & Omphalocele & $\begin{array}{l}\text { amniotic } \\
\text { fluid }\end{array}$ & $\begin{array}{l}\text { Xp21.1(31691172_31766673)x0 } \\
\text { (CMA) }\end{array}$ & $\begin{array}{l}\text { E52- } \\
53\end{array}$ & Y & abortion \\
\hline & & & & & & del & & \\
\hline \multirow[t]{3}{*}{2} & 30 & male & $\begin{array}{l}\text { 1.right aortic } \\
\text { arch }\end{array}$ & $\begin{array}{l}\text { amniotic } \\
\text { fluid }\end{array}$ & $\begin{array}{l}\text { Xp21.2(31016983_31351900)x2 } \\
\text { (CMA) }\end{array}$ & $\begin{array}{l}\text { E61- } \\
79\end{array}$ & Y & abortion \\
\hline & & & $\begin{array}{l}\text { 2.left artery } \\
\text { vagal }\end{array}$ & & & dup & & \\
\hline & & & $\begin{array}{l}\text { 3.left } \\
\text { ventricular } \\
\text { bright spot. }\end{array}$ & & & & & \\
\hline \multirow[t]{2}{*}{3} & $32+1$ & female & 1.NF: $6.8 \mathrm{~mm}$ & $\begin{array}{l}\text { amniotic } \\
\text { fluid }\end{array}$ & $\begin{array}{l}\text { Xp21.2(31182699_31474949)x3 } \\
\text { (CMA) }\end{array}$ & $\begin{array}{l}\text { E58- } \\
74\end{array}$ & Y & $\begin{array}{l}\text { born with } \\
\text { problems }\end{array}$ \\
\hline & & & $\begin{array}{l}\text { 2.Down } \\
\text { risk:1:413 }\end{array}$ & & & dup & & \\
\hline 4 & $31+3$ & male & $\begin{array}{l}\text { sacrococcygeal } \\
\text { vertebrae } \\
\text { dysplasia }\end{array}$ & $\begin{array}{l}\text { amniotic } \\
\text { fluid }\end{array}$ & $\begin{array}{l}\text { Xp21.1(31777925_32152126)x2 } \\
\text { (CMA) }\end{array}$ & $\begin{array}{l}\text { E45- } \\
51 \\
\text { dup }\end{array}$ & Y & abortion \\
\hline \multirow[t]{2}{*}{5} & $24+5$ & female & $\begin{array}{l}\text { Down } \\
\text { risk: } 1: 227\end{array}$ & $\begin{array}{l}\text { amniotic } \\
\text { fluid }\end{array}$ & $\begin{array}{l}\operatorname{dup}(X)(p 21.2) \\
\text { chrX:g.30860000_31260000 }\end{array}$ & $\begin{array}{l}\text { E64- } \\
79\end{array}$ & $\mathrm{~N}$ & abortion \\
\hline & & & & & (CNV-seq) & dup & & \\
\hline \multirow[t]{2}{*}{6} & $22+6$ & female & $\begin{array}{l}\text { Sex } \\
\text { Chromosome }\end{array}$ & $\begin{array}{l}\text { amniotic } \\
\text { fluid }\end{array}$ & $\begin{array}{l}\operatorname{dup}(X) \\
(\text { p21.1)chrX:g.32820000_33560000 }\end{array}$ & E1-7 & $\mathrm{N}$ & born \\
\hline & & & $\begin{array}{l}\text { Number } \\
\text { Variant (NIPT) }\end{array}$ & & (CNV-seq) & dup & & \\
\hline \multirow[t]{3}{*}{7} & $21+2$ & female & 1.skin edema & $\begin{array}{l}\text { aborted } \\
\text { fetus }\end{array}$ & $\begin{array}{l}\operatorname{del}(X)(p 21.1) \\
\text { chrX:g.31760000_32000000 }\end{array}$ & $\begin{array}{l}\text { E45- } \\
51\end{array}$ & Y & \\
\hline & & & & & (CNV-seq) & del & & \\
\hline & & & $\begin{array}{l}\text { 3.bilateral foot } \\
\text { varus }\end{array}$ & & & & & \\
\hline
\end{tabular}

\section{Declarations}

\section{Author information}

Qiuhua Wu-Technician,M.S

Lihui Yang-Technician, Ph.D.

Qiujie Jin-Technician,M.S

Rui Wang-Technician,M.S

Wen Zhai-Technician, Ph.D.

Yating Wang-Technician,M.S 
Fengrui Shi-Technician

Wenjing Cheng-Technician

Bo Cai-Technician

Rong Qiang - Chief Physician of Genetics, MD, Ph.D.

Chao Lou - Attending Physician of Genetics \MD, Ph.D

\section{Author contributions}

CL, QW conceived and wrote the manuscript.

\section{Ethics approval and consent to participate}

Approved by Ethics Committee of Northwest Women's and Children's Hospital

\section{Consent for publication}

All authors approved to publish. All patients signed the informed consent papers and approved to publish

\section{Availability of data and materials}

The datasets used and/or analysed during the current study available from the corresponding author on reasonable request

\section{Competing interests}

The authors declare that they have no competing interests

\section{Acknowledgements}

Not applicable

\section{Funding}

Not applicable

\section{References}

1. Kwiatkowska J, Słomski R. Gen DMD-najwiekszy gen człowieka [DMD gene-the largest human gene]. Postepy Biochem. 1992;38(2):49-55

2. Verhaart IEC, Aartsma-Rus A. Therapeutic developments for Duchenne muscular dystrophy. Nat Rev Neurol. 2019 ;15(7):373-386.

3. Cheung SW, Bi W. Novel applications of array comparative genomic hybridization in molecular diagnostics. Expert Rev Mol Diagn. $2018 ; 18(6): 531-542$.

4. Capkova P, Srovnal J, Capkova Z, Staffova K, Becvarova V, Trkova M, Adamova K, Santava A, Curtisova V, Hajduch M, Prochazka M. MLPA is a practical and complementary alternative to CMA for diagnostic testing in patients with autism spectrum disorders and identifying new candidate CNVs associated with autism. PeerJ. $2019 ; 9 ; 6:$ e6183.

5. Zhu Y, Hu L, Cao D, Ou X, Jiang M. Chromosomal microarray analysis of infertile men with azoospermia factor microdeletions. Gene. $2020 ; 20 ; 735: 144389$. 
6. Yang S, Zhao Y, Tang X, Wang Z, Liu D, Zhang J, Gu Y, Wang L. [Application of chromosomal microarray analysis in prenatal diagnosis of pregnant women with advanced age]. Zhonghua Yi Xue Yi Chuan Xue Za Zhi. 2021 Feb 10;38(2):101-107.

7. Liang D, Peng Y, Lv W, Deng L, Zhang Y, Li H, Yang P, Zhang J, Song Z, Xu G, Cram DS, Wu L. Copy number variation sequencing for comprehensive diagnosis of chromosome disease syndromes. J Mol Diagn. 2014 Sep;16(5):519-526.

8. Waldrop MA, Flanigan KM. Update in Duchenne and Becker muscular dystrophy. Curr Opin Neurol. 2019 ;32(5):722-727.

9. Okubo M, Noguchi S, Hayashi S, Nakamura H, Komaki H, Matsuo M, Nishino I. Exon skipping induced by nonsense/frameshift mutations in DMD gene results in Becker muscular dystrophy. Hum Genet. 2020 ;139(2):247-255.

10. Miyagoe-Suzuki Y, Takeda S. Gene therapy for muscle disease. Exp Cell Res. $2010 ; 316(18): 3087-92$.

11. Yokota T, Duddy W, Partridge T. Optimizing exon skipping therapies for DMD. Acta Myol. $2007 ; 26(3): 179-84$.

12. Kong X, Zhong X, L iu L, Cui S, Yang Y, Kong L. Genetic analysis of 1051 Chinese families with Duchenne/Becker Muscular Dystrophy. BMC Med Genet. $2019 ; 20(1): 139$.

13. Okubo M, Minami N, Goto K, Goto Y, Noguchi S, Mitsuhashi S, Nishino I. Genetic diagnosis of Duchenne/Becker muscular dystrophy using next-generation sequencing: validation analysis of DMD mutations. J Hum Genet. $2016 ; 61$ (6):483-9.

14. Zhong J, Xie Y, Bhandari V, Chen G, Dang Y, Liao H, Zhang J, Lan D. Clinical and genetic characteristics of female dystrophinopathy carriers. Mol Med Rep. $2019 ; 19(4): 3035-3044$.

15. White SJ, den Dunnen JT. Copy number variation in the genome; the human DMD gene as an example. Cytogenet Genome Res. 2006;115(3-4):240-6.

16. Lai KK, Lo IF, Tong TM, Cheng LY, Lam ST. Detecting exon deletions and duplications of the DMD gene using Multiplex Ligationdependent Probe Amplification (MLPA). Clin Biochem. 2006 ;39(4):367-72.

\section{Figures}




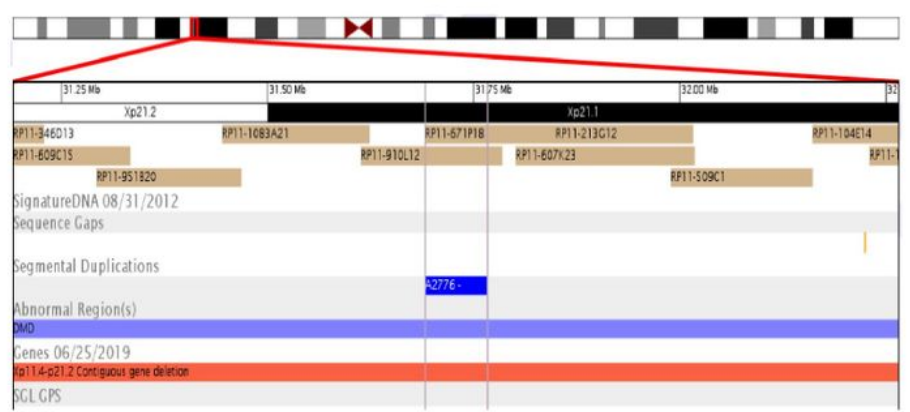

A

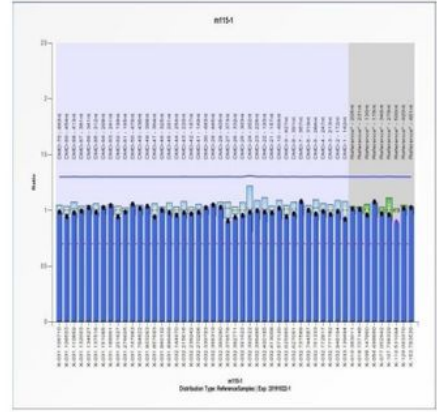

B

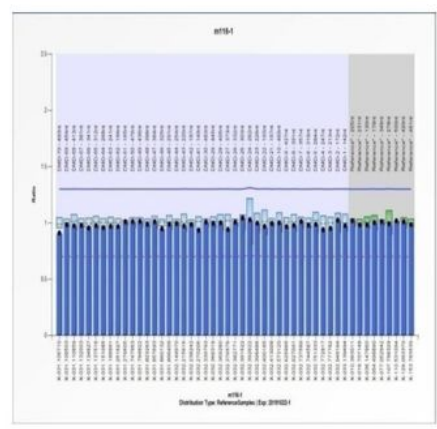

D

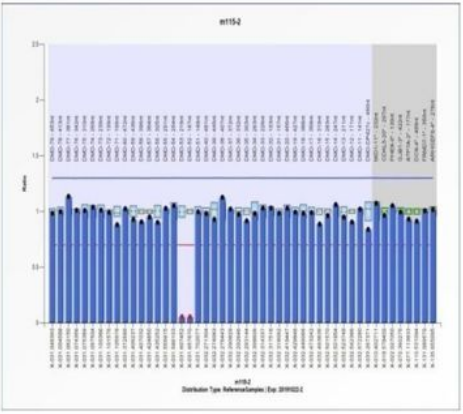

C

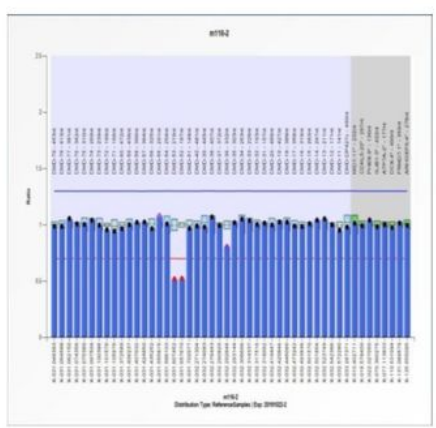

$\mathbf{E}$

Figure 1

Results of case 1 A, Fetus CMA Result: Xp21.1(31691172_31766673)x0; B,C. Fetus MLPA result: E52-53del D,E. Mother MLPA result: E52-53del Mutations inherited from mother 


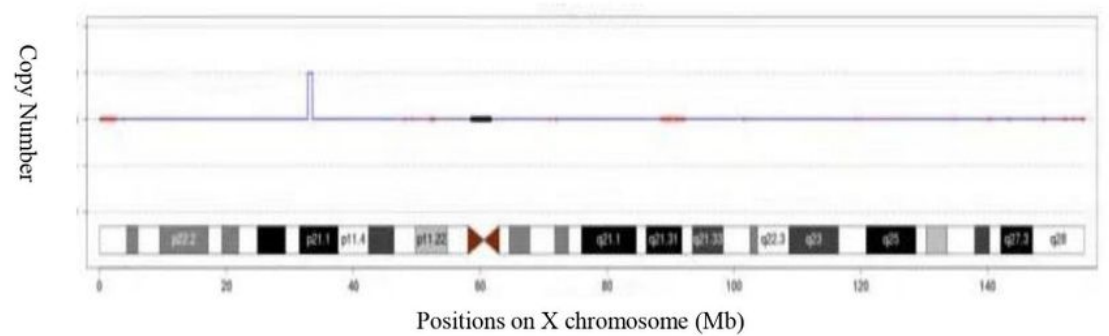

A

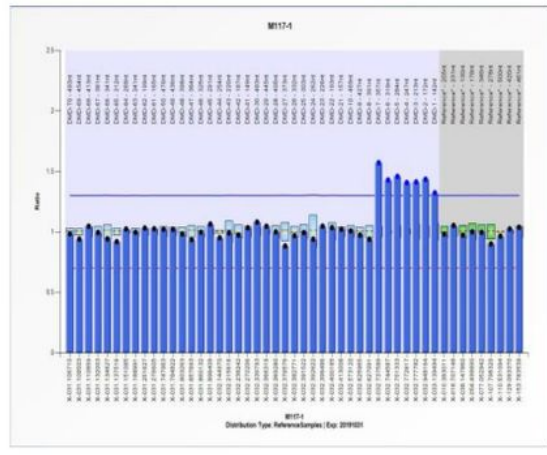

B

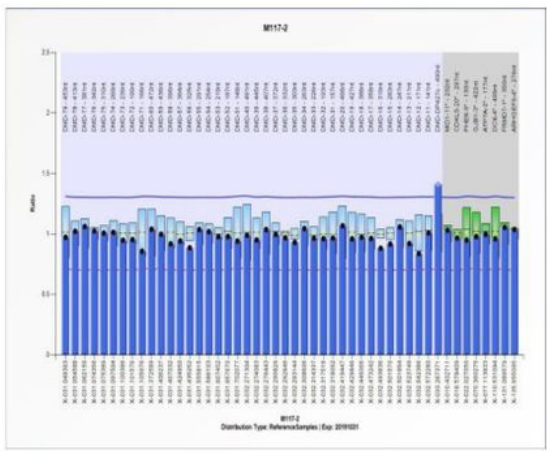

C

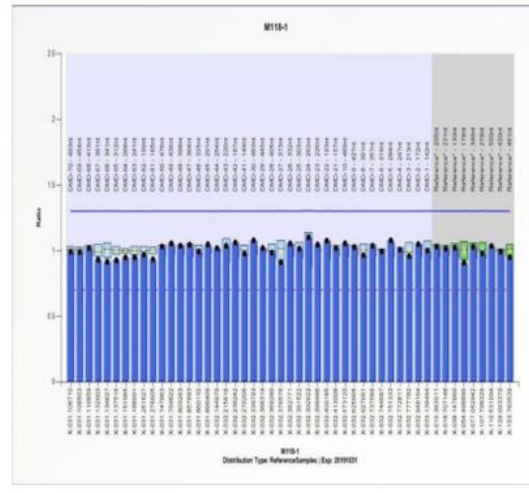

D

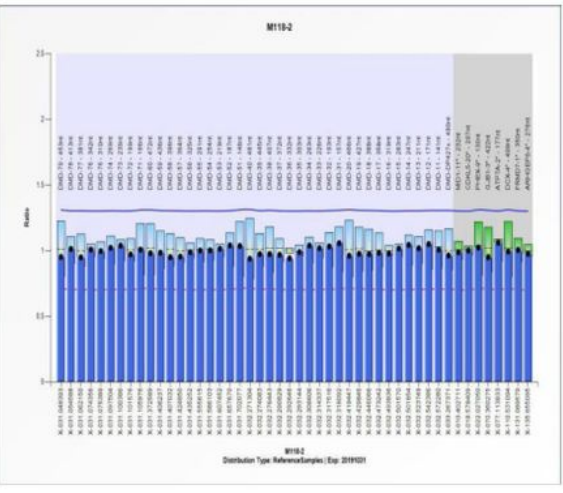

E

Figure 2

Results of case 6 A, Fetus CNV-seq Result: dup(X)(p21.1)chrX:g.32820000_33560000; B,C. Fetus MLPA result: E1-7dup D,E. Mother MLPA result: E1-7dup Mutations did not inherit from mother 